\title{
More Good News!
}

A year ago I could report on some major improvements in the running of Respiration, mainly the much faster handling time of manuscripts, the outstanding performance of the newly structured Editorial Board, and the popularity of the new sections in the journal. I thought that these changes would be noted and gradually lead to some increase in manuscript submission. To my total surprise, and I must confess great satisfaction, the readers of Respiration have reacted very quickly to the new wind by doubling the submission rate from 12 to 24 papers per month, and this steep upward trend is still unbroken! Further, a clear improvement in the quality of original articles has taken place.

This development will enable us to implement a stricter policy for the evaluation of manuscripts. Up to now, the acceptance rate had been just over $50 \%$ for all manuscripts, including commissioned articles. We will now have to limit this rate to about $40 \%$ as we put quality over quantity. The section most influenced are the case reports for which the policy will be very selective. Only contributions reporting new and relevant aspects will be considered. The average number of printed reports will not exceed 2-3 per issue. A case with fascinating diagnostic or therapeutic aspects can, however, be presented in the What Is Your Diagnosis? section, even if its message is not new, provided that it is of high didactic value. Cases with striking illustrative material stand a good chance of being accepted as an Eye Catcher provided that the text is very short. The only section which has not received the desired number of submissions is the Clinico-Pathological Conferences, for which more contributions are welcome.

With the millennium edition we introduce one further section entitled The Opinion Corner, for which we welcome personal, even controversial issues, which may be discussed by leading authorities in the field. Only papers from experts in their respective areas will be considered and will be peer-reviewed as all other material.

The thematic review series for this year is dedicated to cystic fibrosis and consists again of 6 outstanding articles, one per issue. It is edited by P. Gustafsson whose introductory editorial follows these notes.

As the number of accepted manuscripts has increased substantially, we will have to expand the page numbers in all six issues of this year to avoid excessive publication time. For 2000 this will still be possible at the current rates for individual subscribers, an undertaking by the publishing house S. Karger AG, for which the Editorial Board is extremely grateful. The future will tell us, whether the stricter acceptance policy will counterbalance the increasing number of manuscripts, or whether the journal will continue to grow, both in quality and in size. The current trend seems to announce the latter, which is the kind of start into the new millennium I had always hoped for.

A final thought on communication! The discerning reader will have noticed that the Editor-in-Chief has recently moved from Basel, Switzerland to Cape Town, South Africa. The editorial office, however, remains unchanged in Basel, to where all manuscripts should be sent initially. This move happened without any loss in the level or speed of communication between the editor and the office. Such a smooth transition was only possible because of the daily use of e-mail, fax, phone and air courier, and would not have been feasible some years ago. But the main credit and a big thank-you does not go to the electronic media but to Linda Haas, the 'soul' of Respiration at the Basel office, whose continued efficiency and enthusiasm are of vital importance for the increasing success of the journal!

C.T. Bolliger, Cape Town

\begin{tabular}{ll}
\hline KARGER & ( ) 2000 S. Karger AG, Basel \\
Fax +4161306 1234 & 0025-7931/00/0671-0001\$17.50/0 \\
$\begin{array}{l}\text { E-Mail karger@karger.ch } \\
\text { www.karger.com }\end{array}$ & $\begin{array}{l}\text { Accessible online at: } \\
\text { www.karger.com/journals/res }\end{array}$
\end{tabular}

